\title{
Business risk evaluation and management of Iranian commercial insurance companies
}

\author{
Farokh Hessami $^{\mathbf{a}^{*}}$
}

${ }^{a}$ Department of Management Science, University of Tehran, Iran

CH R O N I C L E A B S T RACT

Article history:

Received: November 26, 2017

Received in revised format: November 26, 2017

Accepted: December 12, 2017

Available online:

December 12, 2017

Keywords:

Insurance industry

Risk evaluation and management

Adaptive neuro-fuzzy inference

system (ANFIS)

\begin{abstract}
Nowadays, with the expansion of economic businesses and also the dependency of economic activists on the insurance industry to provide the capitals security, there is now a growing need to identify and evaluate risks of the insurance industry. Therefore, in this study, a comprehensive model was developed to evaluate and manage business risk by reviewing the research literature, extensively. For this purpose, an adaptive neuro-fuzzy inference system (ANFIS) was developed for every business risk after identifying the relevant dimensions and the criteria and collecting the necessary data from the central insurance databases. Finally, a general model was presented to evaluate and manage risks of the insurance industry. Four major problems were also considered: optimal and efficient normalization, optimal training for testing ratio for every neural network, model validation, and the easiness of user communication with the system. The results show that the model can provide an accurate estimation for risk evaluation and management. Thus, this system can be considered as an appropriate tool for business risk evaluation and management of insurance companies. Furthermore, the effectiveness of this method in evaluating and managing the risk at insurance companies can be turned into a neural network and such a neural network can be used as an appropriate decision-making support tool.
\end{abstract}

\section{Introduction}

Nowadays, insurance has been considered as a vital institution in the financial market. It contributes people to reduce the risks that they face in their daily lives. On the other hand, insurance companies are faced with various risks due to insurance policies they issue for policyholders. However, such companies seek certain solutions to reduce their risks (Soleymani et al., 2014). Nowadays, with the expansion of economic businesses and also the dependency of economic activists on the insurance industry to provide the capitals security, and at the same time, the concerns of business companies to fulfill certain obligations to policyholders and maximize their own benefits, there is now a growing need to identify and evaluate risks of the insurance industry (Ghorbani Golsefidi, 2016). In today's complicated world, with the increasing interactions and exchanges, it is greatly important to provide security for economic activists. Since economic activists or investors seek proper solutions to secure their capitals and reduce

\footnotetext{
* Corresponding author.

E-mail address: farokhhessami2004@yahoo.com (F. Hessami) 
the effects of potential risks, insurance companies can be very helpful. In addition, risk and loss are the first words coming to mind when the concept of insurance is discussed (Karimi, 2013).

Nowadays, insurance companies are mainly concerned to fulfill certain obligations for policyholders and maximize their own benefits. For this purpose, monitoring organizations approved specific laws and regulations to maintain the solvency of insurance companies at an acceptable level in every country. Furthermore, managers take precautionary measures and come up with new technical and financial solutions to take the necessary steps in the same direction. One of such cases is proper use of financial mechanisms. Hence, the use of financial mechanisms can improve the financial evaluation power of insurance companies and increase the level of policyholders' trust in such companies. These mechanisms also improve the performances of insurance companies (Paton et al., 2015). The insurance companies should evaluate their solvency to take the risks of policyholders. Risk evaluation is one of the pillars of insurance whether in pricing insurance policies or in reciprocal contracts (Ansah-Adu et al., 2012). In recent years, insurance companies have adopted new methods of risk evaluation for the optimal capital allocation, capital adequacy, and solvency. In traditional insurance companies, the management system of an organization often considers managing the risk of each of obligations and policies; however, it does not pay enough attention to the entire risk of the organization resulting from the aggregation of these risks. Due to the importance of risk evaluation and its application for the management and solvency of insurance companies in this study, we tried to present a system for risk evaluation.

Among the new modeling methods, fuzzy systems are of special importance in different sciences. They are daily used to investigate a wide variety of phenomena (Nilosey, 2016; Tao et al., 2010). Such systems are mainly characterized by the ability to implement human knowledge with the use of specifically verbal concepts and fuzzy rules, nonlinearity, adaptability, and a higher level of accuracy in comparison with other methods when the available data are limited (Gocić et al., 2015). A fuzzy system runs in accordance with the logical if-then rules. The starting point of developing a fuzzy system is to obtain a set of fuzzy if-then rules by using an expert's knowledge or the relevant knowledge (Jamshidi, 2003; Zadeh, 2007). A useful tool can be a method of using the available numerical information to develop fuzzy logic rules. Another new modeling method is an artificial neural network. Such networks are so powerful mainly due to the fact that they can be trained according to training patterns (consistent inputs and outputs) and different training algorithms. Therefore, they can determine the relationships between input and output variables. The initial plans of such models are based on the learning pattern of the human learning system (Pérez-Gandía et al., 2010).

The term ANFIS stands for Adaptive Neuro-Fuzzy Inference System. It has been used widely to investigate phenomena with nonlinear equations (Goodarzi \& Freitas, 2010; Nikolic et al., 2016). Therefore, the hybrid of fuzzy systems based on logical rules, and artificial neural networks which are able to extract knowledge from numerical information, enables us to use the available information to develop a model in addition to benefiting from the human knowledge. Thus, the resultant method is an adaptive neuro-fuzzy inference technique (Riahi-Madvar et al., 2009; Ebrat \& Ghodis, 2014). According to Insurance Bylaw 69 (approved by the High Insurance Council), policyholder risk classifications of International Actuarial Association (IAA), the requirements of International Associations of Insurance Supervisors (IAIS), statistical and modeling constraints on Iranian commercial insurance industry, the risk of a commercial insurance company consists of the following items in Iranian solvency model: insurance or underwriting risk, market risk, credit risk, and liquidity risk (Shahriar, 2014). The aim of this study was to use an intelligent mathematical model to evaluate the risk of the insurance industry to introduce a solvency calculation model for Iranian commercial insurance companies.

Given the fact that the risk of an insurance company was resulted from the aggregation of insurance or underwriting risk, credit risk, market risk, and liquidity risk, four ANFISs were designed in this study. The input of the unwriting risk ANFIS included the premium and compensation obtained from fire insurance, the premium and compensation obtained from cargo insurance, the premium and compensation obtained from accident insurance, and the premium and compensation obtained from passenger 
accident insurance. The input of the market risk ANFIS includes portfolio value and real estate value. Moreover, the input of the credit risk ANFIS included the value of domestic demands and the value of foreign demands. Finally, the input of the liquidity risk ANFIS included current assets and current debts. Therefore, the aim of this study was to evaluate and manage business risk at Iranian commercial business companies with respect to the available information in 2015.

\section{Review of literature}

Many studies have been conducted on risk management and evaluation. However, no comprehensive studies have been carried out on this subject in the insurance industry. Niemeyer (2015) presented a new to evaluate the risk in life insurance. Another goal of the study was to examine the correlation between the two consecutive states at different times. Guo and Huang (2013) presented a theoretical model to determine different risks in the property insurance market in China. For this purpose, the structured VAR model was used. Lu et al. (2012) conducted a study to reach an optimal time insurance agreement facing several sources of risk. The results of the study showed that the optimality of time fractional insurance including expected insurable or uninsurable risks which would be positive, independent, or utility dependent. Then this model was compared with previously riskless models. Moreover, the optimally expected fractional and beneficial changes were analyzed by correcting the dependency and boundary structure.

Ghorbani Golsefidi (2016) conducted a study in which the treatment damages paid by Mellat Insurance (143000 records) were used to develop a data warehouse for multidimensional exploitation and reporting. After eliminating the defects and contradicting data, OLAP processing was used to design a data warehouse of the star topology. Considering the designed model, managers and other employees can observe all the factors affecting the insured risk at the same time. According to the reports on the model, then they can make the necessary decisions. Identifying risk factors contributes insurance companies to reduce the percentage of loss as much as possible by providing clients with an appropriate rate. On the other hand, customer satisfaction and loyalty can be obtained from the clients imposing little loss on the company by providing them reasonable discounts. Nazeri (2013) conducted a study to develop a decision-making model so that insurance companies could predict customer risk and adopt necessary policies. The research methodology was based on a standard data mining process. In other words, the data of previous customers were collected and refined to identify the variables affecting the risk behaviors of customers who were then classified as good (low-risk) and bad (high-risk). A class label was considered for each customer. The results of study showed that the $\mathrm{C} 5$ algorithm has better performance in customer classification in comparison with other algorithms. Hanafizadeh and Rastakhiz (2011) intended to provide solutions for insurance companies to determine the premium rate of car insurance based on the risk level of every customer. They also wanted to contribute insurance organizations to meet their goals and adopt appropriate strategies for each group of customers in order to improve their current positions in the market (Hanafizadeh \& Rastakhis, 2011).

Sehat and Alavi (2010) explained the factors affecting the increase in the payable compensation and the risk intensification related to the third-party insurance activities of companies in details. Finally, they dealt with certain solutions to reduce the risks of the third-party insurance in addition to the effect of the new law of the third-party insurance (approved by the Guardian Council on August 6, 2008) on the risk of this type of insurance. Mousavi et al. (2009) carried out a study in which a fuzzy expert system was introduced as an efficient tool for project risk analysis. Such a fuzzy expert system was designed to evaluate and prioritize project risks was validated scientifically. Manouchehri (2009) believed that risk is a subject which stands right against the luck. All of the insurance contracts, especially the insurance of individuals, are evaluated in accordance with risk and the estimation of risk affecting the destiny of contracts based on the rates of increase or decrease. Therefore, determining the risk of contracts and calculate the premium rate is important. For this purpose, different effects of risk on the insurance contracts of individuals were explained and defined along with different types of risk. 


\section{Methodology}

This study in term of goal is applied and in term of data collection method is quantitative study. The knowledge data base includes knowledge of managers and experts in the field of insurance industry. These experts had enough knowledge about the insurance industry in Iran and with more than ten years of job experience. So, the indicators of insurance such as underwriting risk, market risk, credit risk, and liquidity risks were extracted by using insurance expert opinions. Then the exploratory factor analysis was used in $\operatorname{SPSS}^{1}$ to reduce the available parameters to measure the insurance or underwriting risk, credit risk, market risk, liquidity risk. Data were collect from the almanac published by the Central Insurance in 2015. Then an ANFIS model was developed and evaluated. Fig. 1 shows the schematic view of the research method.

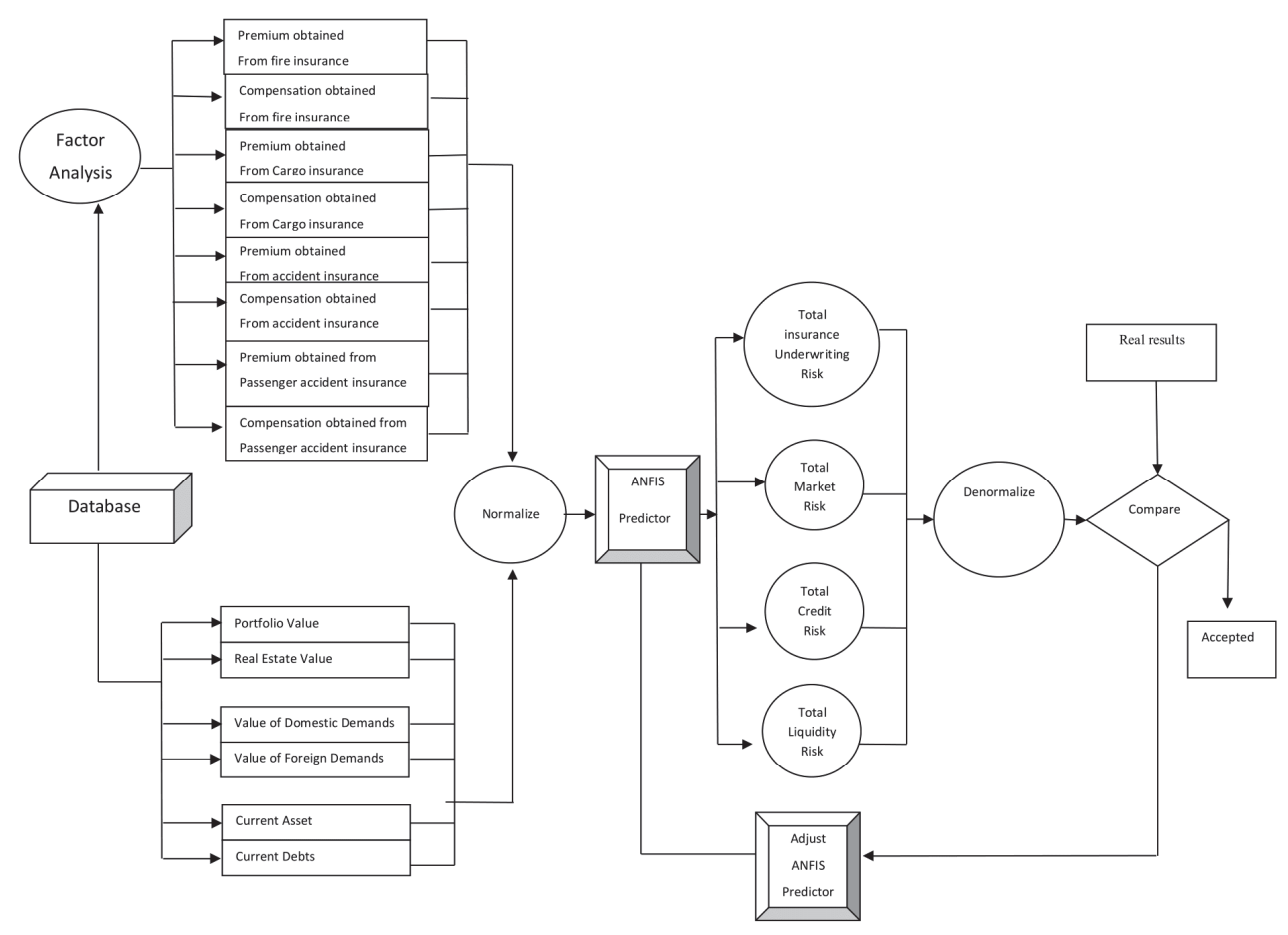

Fig. 1. Research Conceptual Model

In this study, the data were normalized and turned into numbers between 0 and 1 . Then $70 \%$ of data were used to train the research model in which the system use training data to initiate the learning process with a neural network. Furthermore, $15 \%$ of data were used to validate the model. These data were actually used to check the fitness of model and validate the system. Finally, the other $15 \%$ of data were used to test the model. These data were used to check the generality and generalizability of the system. In this model the data were randomly divided into training, validation, and evaluation groups. There are two methods of using a neuro-fuzzy system: grid partitioning and sub-clustering. These two methods are mainly different in how they determine the fuzzy membership function. In the grid partitioning method, users determine the type and the number of membership functions for the input information vector. However, ANFIS determines the type of membership function with respect to the features of input information vector and the available classifications. In this study, the grid partitioning

\footnotetext{
${ }^{1}$ See Statistical Analyses in SPSS by Momeni
} 
method was used along with a bell curve input membership function named Gbellmf and a linear output membership function with four input variables and three membership functions at 100 iterations for the system of calculating insurance or underwriting risk. There were two input variables and five membership functions at 100 iterations in the systems of calculating market risk and credit risk. Finally, there were two input variables and seven membership functions in the system of calculating liquidity risk. These inputs and functions resulted in the desired output which was the score of each risk at insurance companies. A hybrid method of neural networks and fuzzy techniques was used to train the research model. The studies (Alamdari et al., 2013; Riahi \& Ayoob Zadeh, 2009) include the details on how ANFIS was developed. After designing previous steps and ANFIS and system validation, the system was modelled in Simulink. ${ }^{2}$ According to Fig. 1, the inputs are entered into the model after they are obtained. In ANFIS, the inputs (including the premium, maintenance share, and the outgoing revenue of maintenance share in fire, cargo, accident, and passenger accident insurances) are first multiplied by the risk factor declared in Bylaw 69 of the Central Insurance. Then the maximum result is entered into the system. In the next step, the received data are entered into ANFIS, the outputs of which are insurance or underwriting risk, market risk, credit risk, and liquidity risk of an insurance company, respectively. Then the total risk is calculated after denormalizing outputs. The total risk results from the root of total squared risk of the insurance company.

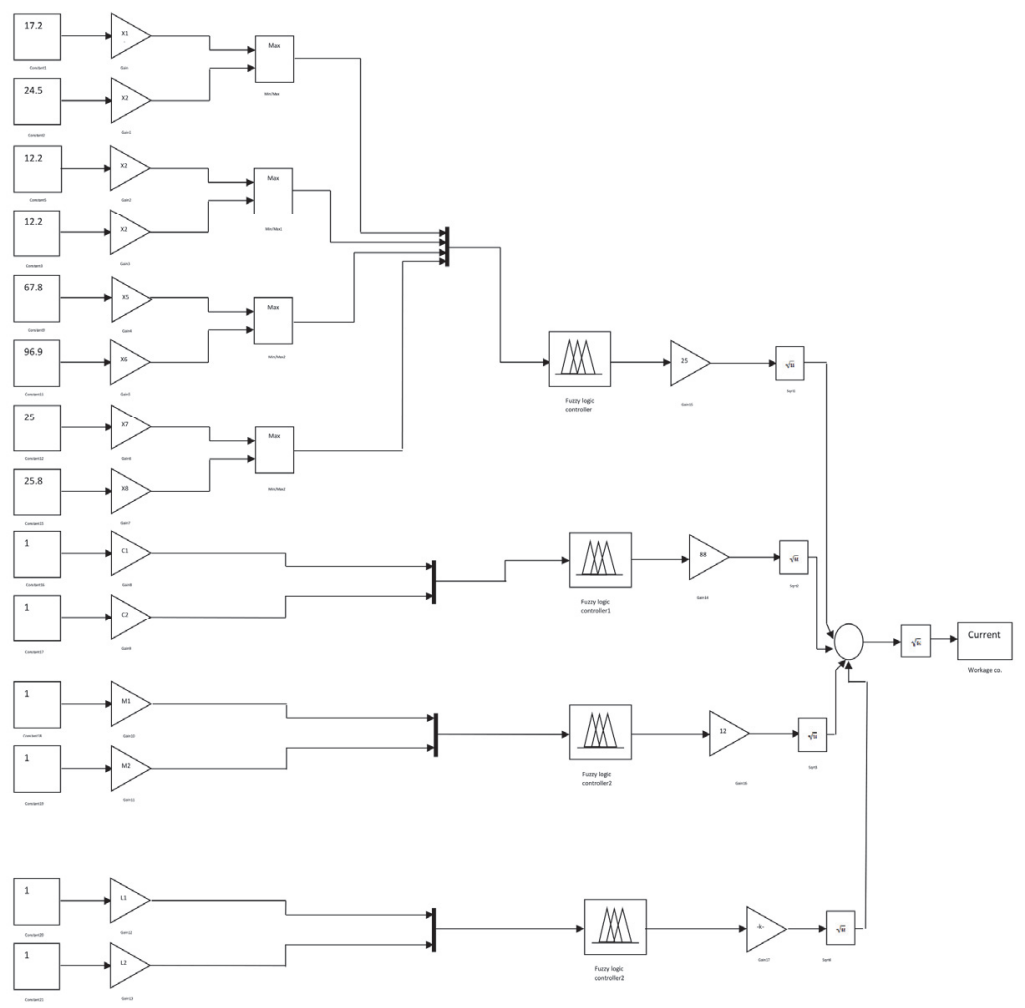

Fig. 2. System Modeling in Simulink

\section{Results}

The collected datasets were used to develop a new model to evaluate risks at insurance companies based on the capabilities of ANFIS. In neural models, nearly $50 \%$ of data were used as testing and validating data, and the other $50 \%$ were used as training data. Moreover, the optimal percentage for MSE, NMSE, MAE and R coefficient was 137.316, 0.2266, 9.6311 and 0.919, respectively (Table 1).

\footnotetext{
${ }^{2}$ Refer to MATLAB and SIMULINK Guide Book.
} 
Table 1

Optimal percentage for training, testing and validating for data used in neural networks

\begin{tabular}{lllllll}
\hline Training\% & Validation\% & Testing\% & MSE & NMSE & MAE & R \\
\hline $\mathbf{5 0}$ & 25 & 25 & 137.316 & 0.2266 & 9.6311 & 0.919 \\
\hline
\end{tabular}

In ANFIS model, $70 \%$ of data were used to train the research model in which the system use training data to initiate the learning process with a neural network. Furthermore, 15\% of data were used to validate the model. These data were actually used to check the fitness of model and validate the system. Finally, the other $15 \%$ of data were used to test the model. These data were used to check the generality and generalizability of the system. At final the optimal percentage for MSE, NMSE, MAE and R coefficient was 289.4521, 0.8745, 15.3125 and 0.878, respectively (Table 2). So, ANFIS model in comparison with the neural networks had desired optimal coefficient and validated.

\section{Table 2}

Optimal percentage for training, testing and validating for data used in ANFIS

\begin{tabular}{lllllll}
\hline Training\% & Validation\% & Testing\% & MSE & NMSE & MAE & R \\
\hline $\mathbf{5 0}$ & 25 & 25 & 139.8457 & 0.2546 & 9.4756 & 0.899 \\
$\mathbf{7 0}$ & 15 & 15 & 289.4521 & 0.8745 & 15.3125 & 0.878 \\
\hline
\end{tabular}

The data were normalized and turned into numbers between 0 and 1. Fig. 3 shows the process of training system for the insurance or underwriting risk. Accordingly, the system controls and corrects the training output instantly by using the validation data in the process of training the model in each period. In other words, validation is done within the training process simultaneously. The same procedure is followed in the other three systems market risk, liquidity risk, and credit risk as shown in Figs. (4-7).

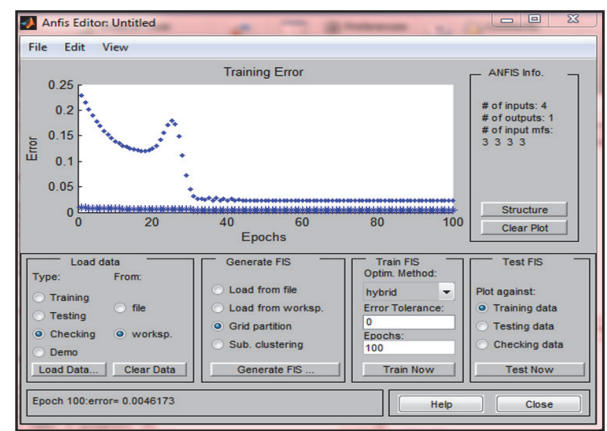

Fig. 3. A View of Neural Network Training and Validation Process in MATLAB

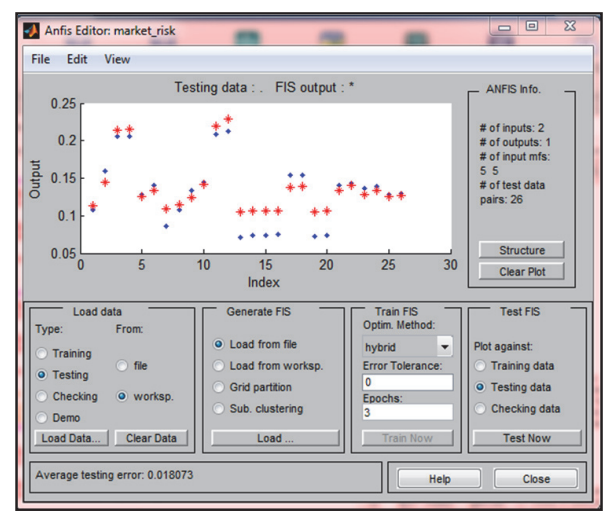

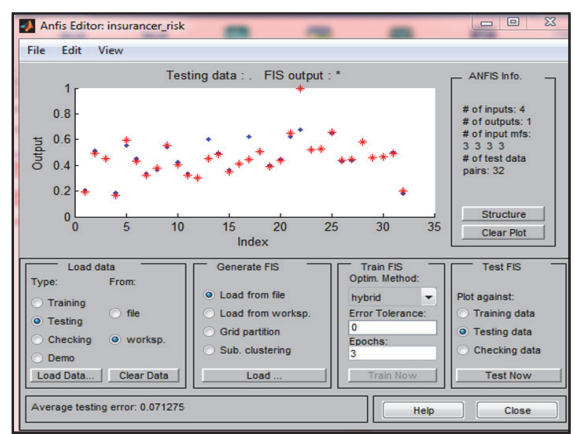

Fig. 4. The Output of Insurance (or Underwriting) Risk Neuro-Fuzzy Network for Testing Data

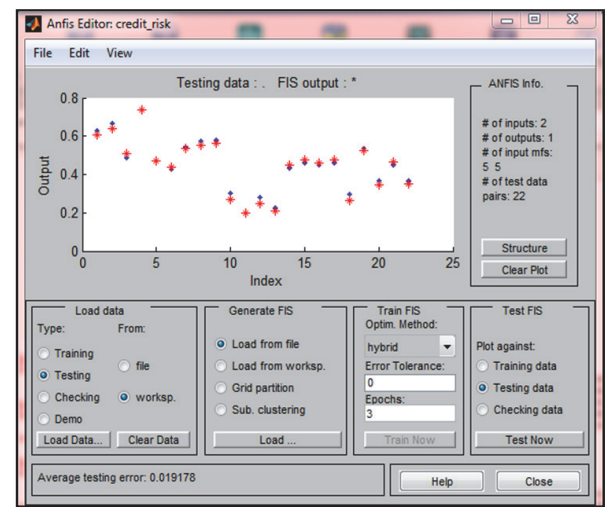

Fig. 5. The Output of Market Risk Neuro-Fuzzy Network for Testing Data 


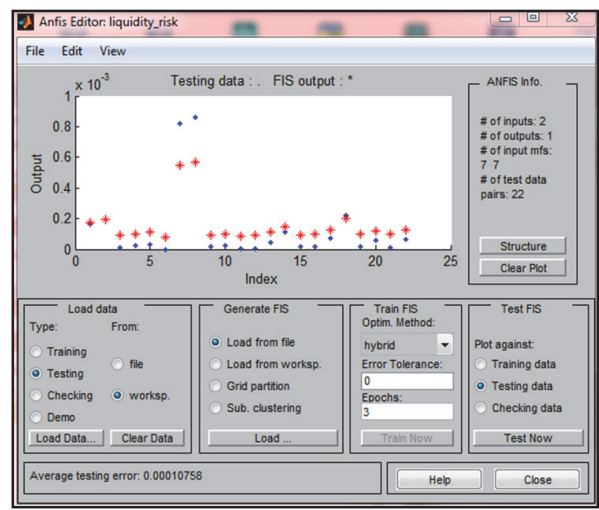

Fig. 7. The Output of Liquidity Risk Neuro-Fuzzy Network for Testing Data

Table 3

The Statistical Features of ANFIS

\begin{tabular}{cccccc}
\hline $\begin{array}{c}\text { Validation } \\
\text { Criteria }\end{array}$ & Optimal Value & $\begin{array}{c}\text { Insurance or Under- } \\
\text { writing Risk }\end{array}$ & $\begin{array}{c}\text { Credit } \\
\text { Risk }\end{array}$ & $\begin{array}{c}\text { Market } \\
\text { Risk }\end{array}$ & $\begin{array}{c}\text { Liquidity } \\
\text { Risk }\end{array}$ \\
\hline SSE & The smaller, the better & 0.8628 & 0.559 & 0.02296 & $9.048 \mathrm{e}-05$ \\
RMSE & $\begin{array}{c}\text { The smaller, the better (smaller than } \\
0.1 \text { is great) }\end{array}$ & 0.06923 & 0.06388 & 0.0125 & 0.0008474 \\
$\mathrm{R}^{2}$ & $\begin{array}{c}\text { Between } 0.6 \text { and } 0.8 \text { is appropriate; be- } \\
\text { tween } 0.8 \text { and 1 is great }\end{array}$ & 0.8588 & 0.8662 & 0.9758 & 0.9995 \\
Adjusted-R ${ }^{2}$ & $\begin{array}{c}\text { Between } 0.6 \text { and 0.8 is appropriate; be- } \\
\text { tween } 0.8 \text { to 1 is great }\end{array}$ & 0.858 & 0.8653 & 0.9756 & 0.9995 \\
MSE & $\begin{array}{c}\text { The smaller, the better (compared with } \\
\text { the two systems) }\end{array}$ & 0.0048 & 0.0046 & $1.5643 \mathrm{e}-04$ & 0.0025 \\
\hline
\end{tabular}

According to Table 3, the neuro-fuzzy model was very accurate and considerably successful. Charts 1 to 4, shows that ANFIS models could accurately obtain the pattern of data and estimate it in the training phase.

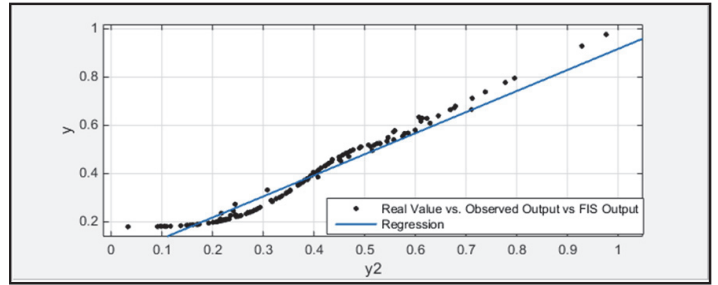

Chart 1. Comparing the Results of Credit Risk ANFIS with Real Data in the Training Phase

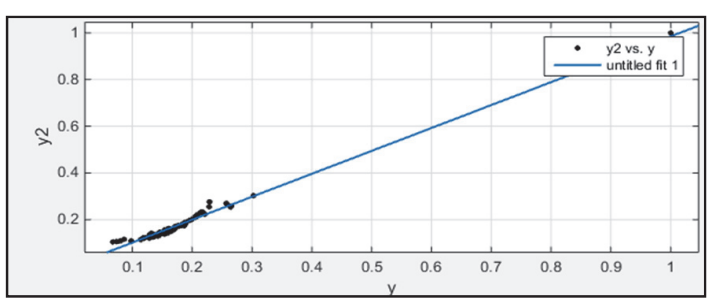

Chart 3. Comparing the Results of Market Risk ANFIS with Real Data in the Training Phase

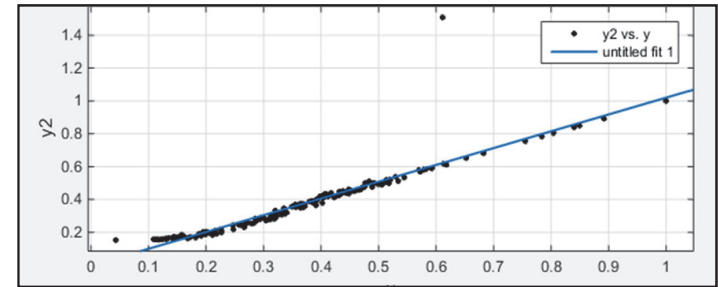

Chart 2. Comparing the Results of Insurance or Underwriting Risk ANFIS with Real Data in the Training Phase

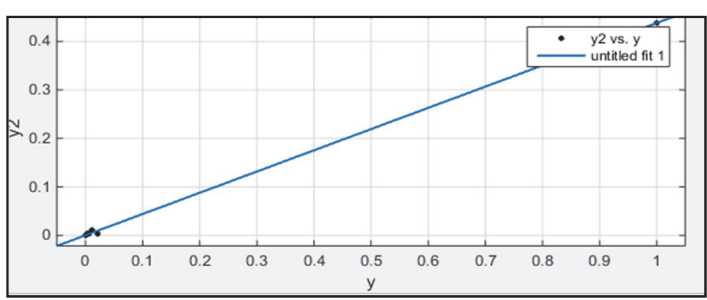

Chart 4. Comparing the Results of Liquidity Risk ANFIS with Real Data in the Training Phase 
After completing the training process and the phases of exterior system validation, testing data can be entered into the system without presenting the real outputs so that the model could predict the requested values. However, the following charts show the output values has been predicted by MATLAB in addition to the fitness of real and predicted outputs in relation to testing data. The following charts (5-8), Figs. (8-11), and Tables (4-7) show the success and high accuracy of ANFIS models.

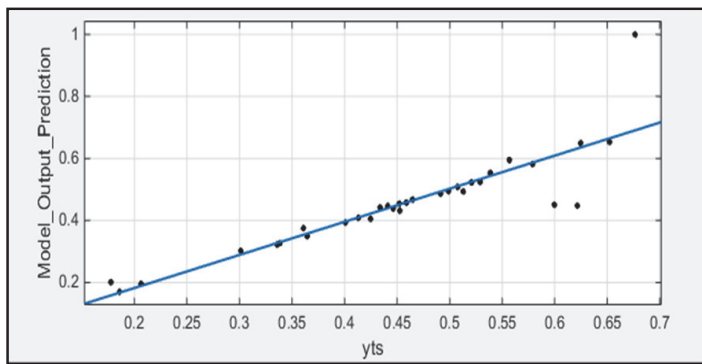

Chart 5. Comparing the Results of the Insurance or Underwriting Risk ANFIS with Real

Data in the Testing Phase

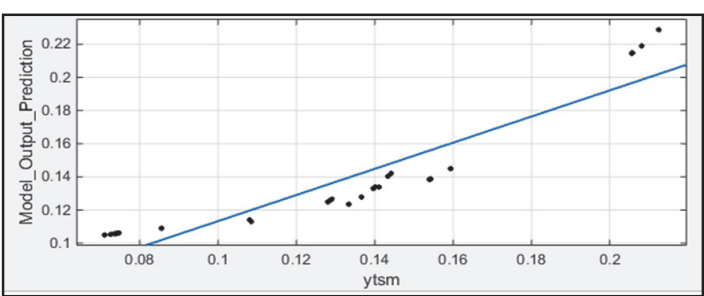

Chart 7. Comparing the Results of Market Risk ANFIS with Real Data in the Testing Phase

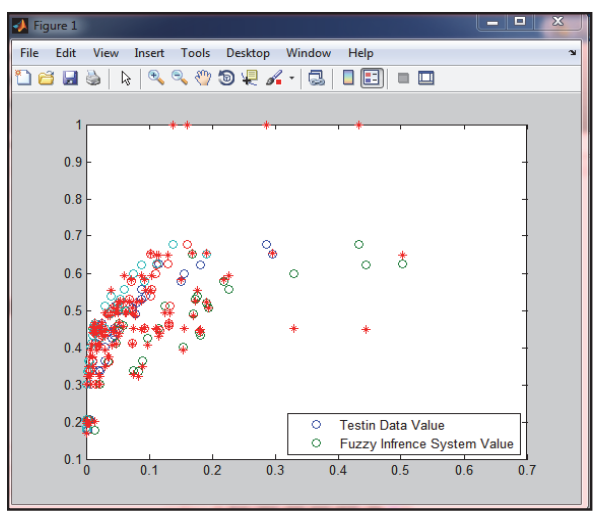

Fig. 8. Displaying real values and the values calculated by the insurance or underwriting risk model for testing data

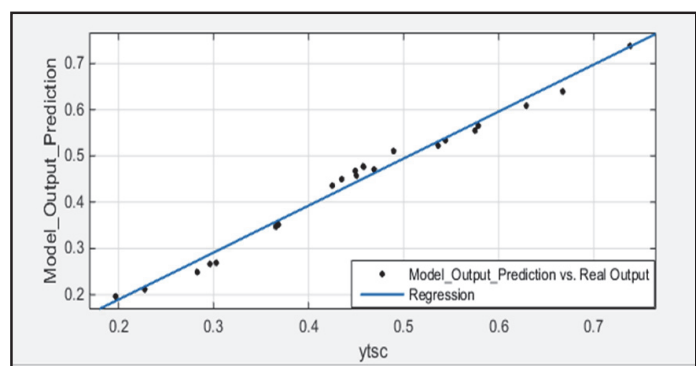

Chart 6. Comparing the Results of Credit Risk ANFIS with Real Data in the Testing Phase

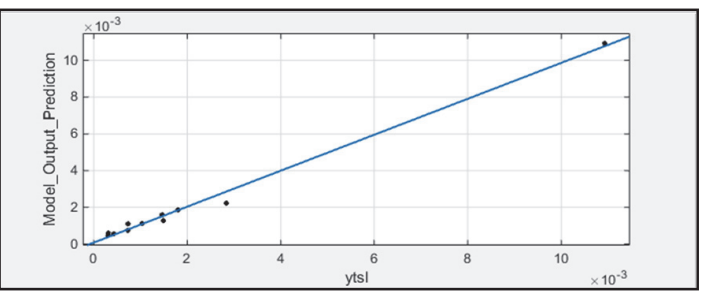

Chart 8. Comparing the Results of Liquidity Risk ANFIS with Real Data in the Testing

Phase

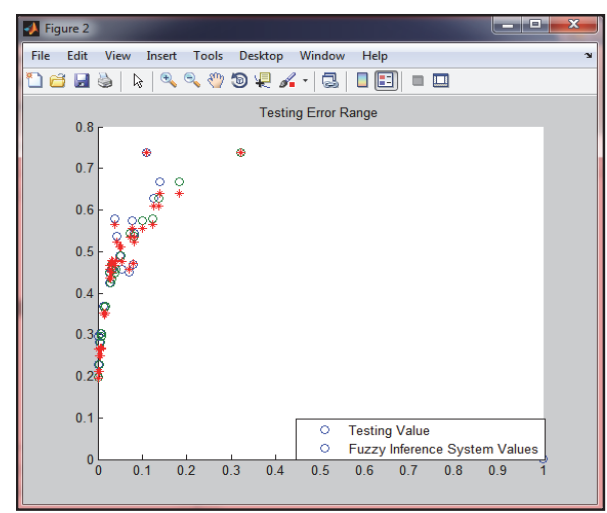

Fig. 9. Displaying real values and the values calculated by the credit risk model for testing data 


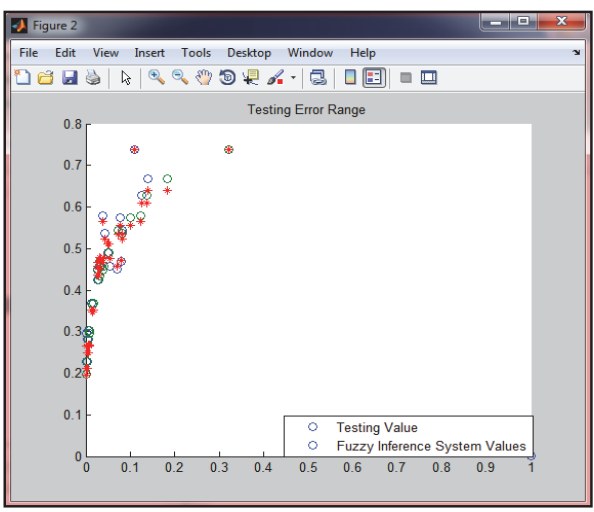

Fig. 10. Displaying real values and the values calculated by the market risk model for testing data

\section{Table 4}

Comparing the Outputs of Insurance or Underwriting Risk Evaluation Model with Real Outputs

\begin{tabular}{cc}
\hline Real Outputs & System Output \\
\hline 5.951073 & 5.6438034 \\
14.8001 & 14.248623 \\
13.04388 & 13.099556 \\
5.36044 & 4.9073868 \\
16.06725 & 17.157441 \\
13.05951 & 12.445654 \\
9.761846 & 9.4205489 \\
10.41269 & 10.83212 \\
15.5467 & 15.979347 \\
12.25592 & 11.699862 \\
9.688525 & 9.3080406 \\
8.690064 & 8.7175469 \\
17.30602 & 13.00958 \\
14.18065 & 14.034397 \\
10.51672 & 10.0757 \\
11.9218 & 11.794939 \\
& \\
\hline
\end{tabular}

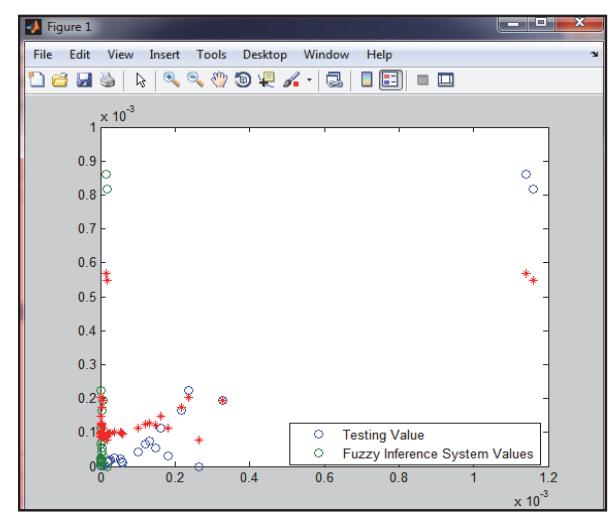

Fig. 11. Displaying real values and the values calculated by the liquidity risk model for testing data

\section{Table 5}

Comparing the Outputs of Credit Risk Evaluation Model with Real Outputs

\begin{tabular}{cc}
\hline Real Outputs & System Data \\
\hline 7.541863 & 7.300358194 \\
8.0020411 & 7.671326058 \\
5.8690365 & 6.124778497 \\
8.8507744 & 8.854441146 \\
5.6218553 & 5.642688195 \\
\hline 5.0954197 & 5.227879389 \\
6.5226524 & 6.401113842 \\
6.8951929 & 6.65319125 \\
6.9363679 & 6.78416766 \\
\hline 3.6318102 & 3.223890057 \\
\hline 2.3611756 & 2.353280617 \\
3.3923974 & 2.983418511 \\
2.7301778 & 2.529286792 \\
\hline 5.213519 & 5.392508438 \\
\hline 5.4902332 & 5.713954966 \\
\hline 5.3981194 & 5.486986412 \\
\hline 5.4845735 & 5.727758581 \\
\hline 3.5514244 & 3.195259187 \\
\hline
\end{tabular}

However, the above charts show the output values has been predicted by MATLAB in addition to the fitness of real and predicted outputs in relation to testing data. Also the above results show the success and high accuracy of ANFIS models. 
Table 6

Comparing the Outputs of Market Risk Evaluation Model with Real Outputs

\begin{tabular}{cc}
\hline Real Output & System Output \\
\hline 14.0614976 & 14.6508314 \\
\hline 8.74686892 & 14.6789876 \\
9.64026876 & 8.53795142 \\
\hline 5.84302262 & 9.15205951 \\
7.38259822 & 7.4558175 \\
\hline 9.11167555 & 7.79709668 \\
9.85046913 & 8.44455891 \\
\hline 14.2233135 & 9.71166586 \\
14.5204995 & 14.964536 \\
\hline 4.85331523 & 15.631846 \\
\hline 5.06102229 & 7.17562433 \\
\hline 5.05120083 & 7.2409061 \\
\hline 5.09960319 & 7.23700879 \\
\hline 10.5182394 & 7.25701571 \\
\hline 10.542159 & 9.45497235 \\
\hline
\end{tabular}

Table 7

Comparing the Outputs of Liquidity Risk Evaluation Model with Real Outputs

\begin{tabular}{cc}
\hline Real Output & System Output \\
\hline 581083.7 & 581080.732 \\
95936.15 & 98909.6744 \\
150813.5 & 118274.168 \\
38936.52 & 58637.5858 \\
16490.88 & 24747.0357 \\
77711.32 & 84648.2766 \\
16503.77 & 32163.5275 \\
\hline 55030.88 & 59917.928 \\
\hline 22849.53 & 29593.4673 \\
\hline 79205.35 & 67722.1748 \\
\hline
\end{tabular}

\section{Conclusion}

In this study, ANFIS was used to evaluate and manage the risks of Iranian insurance companies. Many of the conventional techniques due to probabilities and random processes cannot apply properly the relationships with ambiguous and fuzzy data. Therefore, ANFIS was validated by collecting a proper number of data and executed and trained in the software. The results have shown that ANFIS could be used to provide appropriate estimates for the future and the evaluation of the current status. What the outputs show clearly is that numerous data were used in this system so that it could perform the following way: First, a neural network was designed. Then nearly $30 \%$ of data were used as testing and validating the data, and the other $70 \%$ were used as training the data. Then the system was reconfigured. The same data were reused to evaluate the behavior of the system. The resultant numbers showed that the system could provide an accurate estimate of risk evaluation.

Therefore, the resultant system can be considered as the proper tool for risk evaluation. Unlike statistical and mathematical modeling methods, ANFIS is based on data. Thus, it eliminates the assumptions which may lead to oversimplification. So ANFIS relies only on the nature of realities, and it can be considered a reliable method.

Furthermore, the effectiveness of this method in risk evaluation of Iranian commercial insurance companies can contributes to take the steps and consider factors such as adequate data, the appropriate neural network configuration, the use of proper training methods, appropriate performance evaluation, and conversion into a neural network. Therefore, ANFIS can be considered as a beneficial decisionmaking support tool. 


\section{References}

Alamdari, A., Doosti, A., Karimi Mahabadi, R., \& Rajabi, Z. (2013). Special Subjects on Electrical and Computer Engineering in MATLAB, Negarandeh Danesh Publications.

Ansah-Adu, K., Andoh, C., \& Abor, J. (2011). Evaluating the cost efficiency of insurance companies in Ghana. The Journal of Risk Finance, 13(1), 61-76.

ASCE Task Committee on Application of Artificial Neural Networks in Hydrology. (2000). Artificial neural networks in hydrology. I: Preliminary concepts. Journal of hydrologic engineering, 5(2), $115-123$.

Doskočil, R. (2017). Evaluating the Creditworthiness of a Client in the Insurance Industry Using Adaptive Neuro-Fuzzy Inference System. Engineering Economics, 28(1), 15-24.

Ebrat, M., \& Ghodsi, R. (2014). Construction project risk assessment by using adaptive-network-based fuzzy inference system: An empirical study. KSCE Journal of Civil Engineering, 18(5), 1213-1227.

Fathi, M., \& \& Zamani Osgooy, F. (2014). Advanced MATLAB Programming with GUI and C/C++, Nashr-e Oloom Kanoon

Ghorbani Golsefidi, H. (2016). Solutions for Designing a Risk Evaluation model in Health Insurances Using OLAP (Mellat Insurance), a Master's Thesis, Payame Noor University (Ministry of Science, Research, and Technology), Payame Noor University of Tehran Province, Tehran West Branch.

Gocić, M., Motamedi, S., Shamshirband, S., Petković, D., \& Hashim, R. (2015). Potential of adaptive neuro-fuzzy inference system for evaluation of drought indices. Stochastic environmental research and risk assessment, 29(8), 1993-2002.

Goodarzi, M., \& Freitas, M. P. (2010). MIA-QSAR coupled to principal component analysis-adaptive neuro-fuzzy inference systems (PCA-ANFIS) for the modeling of the anti-HIV reverse transcriptase activities of TIBO derivatives. European journal of medicinal chemistry, 45(4), 1352-1358.

Guo, F., \& Huang, Y. S. (2013). Identifying permanent and transitory risks in the Chinese property insurance market. The North American Journal of Economics and Finance, 26, 689-704.

Jamshidi, M. (2003). Tools for intelligent control: fuzzy controllers, neural networks and genetic algorithms. Philosophical Transactions of the Royal Society of London A: Mathematical, Physical and Engineering Sciences, 361(1809), 1781-1808.

Hanafi Zadeh, P., \& Rastakhiz, N. (2011). A model for classifying the risks of car insurance customers based on risk using data mining techniques, Insurance Research Journal, 2, 55-81.

Karimi, S. M. (2013). Evaluating Iran's insurance industry and explaining the future outlook. The Seasonal Journal of Economic and Financial Policies, Special Issue on the State's Economic Record, 2, 183-202

Lu, Z., Liu, L., Zhang, J., \& Meng, L. (2012). Optimal insurance under multiple sources of risk with positive dependence. Insurance: Mathematics and Economics, 51(2), 462-471.

Manouchehri, M. (2009). The Role of Risk in the Insurance Contracts of Individuals, Kanoon Monthly Journal, 94.

Momeni, M., \& Ghayoomi, A. (2011). Statistical Analyses in SPSS, Moalef.

Mousavi, M., Kavian Pour, J., \& Sirfian Pour, H. (2009). A fuzzy expert system for risk management of projects. The Fifth International Conference on Project Management.

Nazeri, A. (2013). Developing a risk reduction model in Iran's car insurance industry using data mining techniques, A Master's Thesis, Faculty of Engineering, Tarbiat Modares University, Ministry of Science, Research, and Technology.

Niemeyer, A. (2015). Safety margins for systematic biometric and financial risk in a semi-Markov life insurance framework. Risks, 3(1), 35-60.

Nikolić, V., Petković, D., Por, L. Y., Shamshirband, S., Zamani, M., Ćojbašić, Ž., \& Motamedi, S. (2016). Potential of neuro-fuzzy methodology to estimate noise level of wind turbines. Mechanical Systems and Signal Processing, 66, 715-722.

Nilosey, A. (2016). FPGA based diabetic patient health monitoring using fuzzy neural network. International Journal of Science and Research, 5(10), 394-396. 
Paton, B., Bahna-Nolan, M., Isherwood, J., Scheinerman, D., Schlinsog, J., \& Sen, S. (2015). Life insurance regulatory structures and strategy EU compared with US, a preliminary survey. Centre for risk and insurance studies, Notingham Univercity Business School. pp. 1-92.

Pérez-Gandía, C., Facchinetti, A., Sparacino, G., Cobelli, C., Gómez, E. J., Rigla, M., ... \& Hernando, M. E. (2010). Artificial neural network algorithm for online glucose prediction from continuous glucose monitoring. Diabetes technology \& therapeutics, 12(1), 81-88.

Riahi-Madvar, H., Ayyoubzadeh, S. A., Khadangi, E., \& Ebadzadeh, M. M. (2009). An expert system for predicting longitudinal dispersion coefficient in natural streams by using ANFIS. Expert Systems with Applications, 36(4), 8589-8596.

Sehat, S. V., \& Alavi, S. (2010). The necessity of using risk management knowledge in the third-party insurance and the effect of the new law of the third-party insurance on the relevant risk. The Monthly Journal of News on the World of Insurance, No. 145.

Shahriar, B. (2014). Risk management basics and monitoring insolvency of insurance companies, Insurance Research Center (Affiliated with Central Insurance of Iran)

Soleymani, S., \& Sadeghi Shahdani, Fatanat, M. (2014). Designing an insurance joint investment basket to increase reassurance capacity. The Scientific and Research Seasonal Journal of Investment Knowledge, Iranian Financial Engineering Association, 3(9).

Tao, C. W., Taur, J., Chang, J. H., \& Su, S. F. (2010). Adaptive fuzzy switched swing-up and sliding control for the double-pendulum-and-cart system. IEEE Transactions on Systems, Man, and Cybernetics, Part B (Cybernetics), 40(1), 241-252.

Zadeh, L. A. (2007). Fuzzy logic as the logic of natural languages. In Analysis and Design of Intelligent Systems Using Soft Computing Techniques (pp. 1-2). Springer, Berlin, Heidelberg.

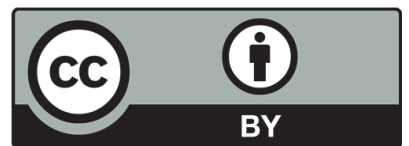

(C) 2018 by the authors; licensee Growing Science, Canada. This is an open access article distributed under the terms and conditions of the Creative Commons Attribution (CC-BY) license (http://creativecommons.org/licenses/by/4.0/). 